\title{
Advanced mathematical model of fuel supply operating process and results of calculations of fuel supply parameters for diesel engine running on composite rapeseed-mineral fuel
}

\author{
Alexander Averyanov ${ }^{1, *}$, Evgeniy Rotanov $^{2}$, and Stanislav Vlasov ${ }^{1}$ \\ ${ }^{1}$ Federal State Autonomous Educational Institution of Higher Education National Research Nuclear \\ University MEPhI (Moscow Engineering Physics Institute), Moscow, Russian Federation \\ ${ }^{2}$ Technological Institute, a branch of the Federal State Budgetary Higher Education Institution "P.A. \\ Stolypin Ulyanovsk State Agrarian University ", Ulyanovsk, Russian Federation
}

\begin{abstract}
Results of theoretical studies are presented, their purpose was to assess the effect of heating of diesel composite fuel on cycle fuel supply and fuel pressure in the above-plunger space of a high-pressure fuel pump (HPFP). A refined mathematical model of the fuel supply process is described, which takes into account the concentration of rapeseed oil in composite rapeseed-mineral fuel and its physical properties, and theoretical justification of a method for determining the mean effective flow crosssection of nozzles and pressure fuel tubing is presented. The analysis results showed that with an increase in the concentration of rapeseed oil in composite diesel fuel and the revolution rate of HPFP camshaft at a temperature of $30^{\circ} \mathrm{C}$, a sharp decrease in the cycle fuel supply is observed which is smoother at heating. The same trend is observed with a change in the fuel pressure in the above-plunger space of HPFP.
\end{abstract}

\section{Introduction}

The problem of creating a diesel engine able to run on various types of fuel has not been completely solved yet. The main cause making it difficult to solve this problem is the difference in the physical properties of fuels used in diesel engines. The multi-fuel diesel engine problem solution comes down to fuel system issues. The objective is to ensure the high quality of fuel system operation on various fuels. It is known that the parameters of the fuel supply process can not be calculated without accounting for the physical constants of fuel, the main of which are compressibility, viscosity, density, surface tension, evaporation or fraction composition.

\footnotetext{
*Corresponding author: averyanovs.as@mail.ru
} 


\section{Experimental procedure}

To determine the hydrodynamic parameters of a direct-action diesel fuel system, a system of partial difference equations is used simulating the process of fuel flow in the pressure fuel tubing in the form of a one-dimensional isothermal unsteady flow of viscous and compressible fuel of constant density, and a system of boundary equations simulating the conditions of the process flow at the end points of the pressure fuel tubing (at the nozzle side and at the pump side) based on the change in the fuel volume of fuel per unit time $(\mathrm{dV} / \mathrm{dt})$ in the compression cavities [in the discharge chamber $\left(\mathrm{VH}_{\mathrm{H}}\right)$, the nipple of the discharge valve ( $\left.\mathrm{VH}^{\prime}\right)$, and in the pocket of the injector nozzle $(\mathrm{V} \phi)$.

For that, the following assumptions were taken:

- the flow of viscous compressible fuel is one-dimensional and its state is isothermal (the fuel temperature is constant and averaged for the whole HPL over the entire injection period);

- fuel parameters (density and velocity of pressure wave propagation) are constant over the entire injection period;

- fuel pressure is equal at any point of enclosed volume (in the cavities above the plunger, valve nipple, and nozzle);

- gas phase impact is taken into account;

- compressibility of fuel and gas phase depends on pressure;

- the compressibility factor $(\gamma)$ represents not only a relative change in volume with a change in pressure, but also a relative change in density with a change in pressure, i.e.

$$
\gamma=\left|\frac{d V}{V} \cdot \frac{1}{d P}\right|=\left|\frac{d \rho}{\rho} \cdot \frac{1}{d P}\right|
$$

In fact, due to the fuel compressibility and its friction on inner HPL surfaces, heat is released. Heat is also released due to the fuel throttling in flow cross-sections of the hydraulic path. This leads to fuel heating and to an increase in its temperature.

In the equations simulating the injection process at the end points of the pressure fuel tubing (at the nozzle side and at the pump side), the change in volume in the compression cavities resulting from not only the fuel compressibility, but

also from its heat-generated expansion shall be taken to the account.

In this connection, the equations of volume balance of boundary conditions will look as follows:

a) at the outlet of the nozzle of the high pressure fuel pump 


$$
\left\{\begin{array}{c}
\gamma_{\mathrm{H}} V_{H} \frac{d p_{H}}{d t}=f_{\Pi} C_{\Pi}-k_{0}(\mu f)_{0} \sqrt{\frac{2}{\rho}} \sqrt{\left|p_{\mathrm{H}}-p_{\mathrm{Bc}}\right|}-k_{\text {щ }}(\mu f)_{щ} \sqrt{\frac{1}{1-k_{\kappa}^{2}}} \times \\
\times \sqrt{\frac{2}{\rho}} \sqrt{\left|p_{\mathrm{H}}-p_{H}^{\prime}\right|}-f_{\kappa} \frac{d y}{d t}-\frac{1}{k_{1}} z_{1}-\frac{1}{k_{2}} z_{2}+\beta_{H} V_{H} \frac{d T_{H}}{d t} ; \\
(\text { equation of volume balance in the discharge chamber }) \\
\gamma_{\mathrm{H}} V_{H} \frac{d p_{H}}{d t}=k_{щ}(\mu f)_{щ} \sqrt{\frac{1}{1-k_{\kappa}^{2}} \times \sqrt{\frac{2}{\rho}} \sqrt{\left|p_{\mathrm{H}}-p_{H}^{\prime}\right|}+f_{\kappa} \frac{d y}{d t}-f_{T \Pi} u_{0}+\beta_{H} V_{H} \frac{d T_{H}}{d t}} \\
(\text { volumetric balance equation in the valve cavity) } \\
\mathrm{M}_{1} \frac{d^{2} y}{d t^{2}}=f_{\mathrm{\kappa}}\left(p_{\mathrm{H}}-p_{H}^{\prime}\right)+\frac{f_{\kappa}-f_{\kappa}^{\prime}}{1+k_{\kappa}^{2}}\left(p_{\mathrm{H}}-p_{H}^{\prime}\right)-f_{\kappa} p_{\kappa o}-\delta h_{\kappa}, \\
\text { (equation of equilibrium of the valve and moving parts with it) }
\end{array}\right.
$$

\section{b) at the outlet of the pressure fuel tubing}

$$
\left\{\begin{array}{c}
\gamma_{\phi} V_{\phi} \frac{d p_{н \phi}}{d t}=f_{T \Pi} u_{n}-k_{\phi}(\mu f)_{\phi} \sqrt{\frac{2}{\rho}} \sqrt{p_{\phi}-p_{Ц}}-f_{\kappa} \frac{d z}{d t}-\frac{1}{k_{3}} z_{3}+\beta_{\phi} V_{\phi} \frac{d T_{\phi}}{d t} ; \\
\text { (equation of volume balance in the pocket of the atomizer body) } \\
\mathrm{M}_{2} \frac{d^{2} z}{d t^{2}}=\left(f_{\mathrm{И}}-f_{\mathrm{И}}^{\prime}\right)\left(p_{\phi}-p_{\phi о}\right)-f_{И}^{\prime} p_{\phi}^{\prime}-\delta^{\prime} h_{И},
\end{array}\right.
$$

(equilibrium equation for the needle and moving parts)

where $\mathrm{k}$ is the hydraulic resistance factor $\left(\kappa=\lambda \frac{c^{2}}{d} ; \lambda\right.$ is the linear loss coefficient; $\mathrm{d}$ is the internal diameter of the pressure fuel tubing, $\mathrm{m}$; $\mathrm{a}$ is the velocity of pressure wave propagation, $\mathrm{m} / \mathrm{s} ; \mathrm{V}_{\mathrm{H}}, \mathrm{V}_{\mathrm{H}}^{\prime}, \mathrm{V}_{\phi}$ and $\mathrm{p}_{\mathrm{H}}, \mathrm{p}_{\mathrm{H}}, \mathrm{p}_{\phi}$ are the volume and pressure in the discharge chamber, at at the outlet of the nozzle of the high pressure fuel pump, and in the pocket of the injector nozzle; $p_{\mathrm{Bc}}, \mathrm{p}_{\text {ц }}$ is the fuel pressure at the intake ports of the plunger bushing and in the cylinder, $\mathrm{Pa} ; \mathrm{p}_{\text {ко }}, \mathrm{p}_{\text {фо }}$ is the pressure at the moment of the start of the movement of the discharge valve and nozzle, $\mathrm{Pa} ; \mathrm{p}_{\phi}$ is the current injection pressure; $\mathrm{f}_{\Pi}, \mathrm{f}_{\mathrm{K}}$, $\mathrm{f}_{\mathrm{K}}, \mathrm{f}_{\text {and }}, \mathrm{f}_{\mathrm{\Psi}}, \mathrm{f}_{\mathrm{T \Pi}}$ is the area of the cross-section of the plunger, of the discharge valve along the collar, of the discharge valve along the tongues, of the nozzle needle, of the gap between the valve and the seat, and of the pressure fuel tubing (clear) $\mathrm{mm}^{2}$; velocity of moving parts (plunger $\left(c_{п}\right)$, discharge valve $\left(c_{\kappa}\right)$, needle $\left.\left(c_{и}\right)\right), \mathrm{m} / \mathrm{s} ; \mathrm{h}, \mathrm{y}, \mathrm{z}$ is the current movement of the plunger, discharge valve and needle, $m ; u_{0}, u_{\Pi}$ is the fuel flow at the inlet and outlet of the fuel tubing, $\mathrm{m} / \mathrm{s} ; \mathrm{z}_{1}, \mathrm{z}_{2}, \mathrm{z}_{3}$ is fuel leakage through the gaps in the spool part of the plunger, the piston part of the plunger, between the needle and the nozzle body, $\mathrm{m}^{3} ; \delta, \delta^{\prime}$ is the tension of the valve spring and the needle, $\mathrm{kg} / \mathrm{s}^{2} ; \mathrm{h}_{\mathrm{\kappa}}, \mathrm{h}_{\mathrm{и}}$ is the valve and needle stroke, $\mathrm{m} ;(\mu \mathrm{f})_{0},(\mu \mathrm{f})_{\phi}$ is the effective flow cross-section of the plunger bushing slots and nozzle assembly, $\mathrm{m}^{2} ; \mu_{\mathrm{m}}$ is the coefficient of fuel flow through the gap between the valve and the seat; $\mathrm{k}_{\mathrm{K}}$ is the coefficient taking into account the fuel throttling when it flows along the valve tongues; $\mathrm{dh} / \mathrm{dt}, \mathrm{dy} / \mathrm{dt}, \mathrm{dz} / \mathrm{dt}$ is the speed of movement of the plunger, valve, and needle, $\mathrm{m} / \mathrm{s} ; \mathrm{M}_{1}$ is the sum of the weight of the valve and one third of the weight of its spring, $\mathrm{kg} ; \mathrm{M}_{2}$ is the sum of the weight of the needle, of the pusher and one-third of the weight of its spring, $\mathrm{kg} ; \mathrm{T}_{\mathrm{H}}, \mathrm{T}_{\mathrm{H}}{ }^{\prime}, \mathrm{T}_{\phi}$ is fuel temperature in the discharge chamber, valve chamber, and in the pocket of the injector nozzle, $\mathrm{K} ; \mathrm{k}_{\mathrm{o}}, \mathrm{k}_{\mathrm{\Psi}}, \mathrm{k}_{\phi}, \mathrm{k}_{1}, \mathrm{k}_{2}, \mathrm{k}_{3}$ are coefficients taking into account the effect of the temperature on the fuel consumption rate through the 
cut-off liner slot, the gap in the discharge valve, nozzle orifices, gaps in the plunger and spool section of the plunger, and injector nozzle gaps.

With an increase in the temperature, fuel leakage through the gaps increases. Therefore, in order to take into account the effect of the temperature on the fuel consumption through the shut-off liner slot and the discharge valve gap, as well as on leakage through the gaps in the precision pairs, adjustments were made in the right-hand side of the equations of volume balance (1.2) and (1.3):

$$
\begin{aligned}
& k_{0}=\left[(\mu f)_{0} \sqrt{\frac{2}{\rho(P, T)}} \sqrt{\left|p_{\mathrm{H}}-p_{\mathrm{BC}}\right|}\right] /\left[(\mu f)_{0} \sqrt{\frac{2}{\rho}} \sqrt{\left|p_{\mathrm{H}}-p_{\mathrm{BC}}\right|}\right] ; \\
& k_{щ}=\left[(\mu f)_{u} \sqrt{\frac{1}{1-k_{\kappa}^{2}}} \sqrt{\frac{2}{\rho(P, T)}} \sqrt{\left|p_{\mathrm{H}}-p_{\mathrm{BC}}\right|}\right] /\left[(\mu f)_{u} \sqrt{\frac{1}{1-k_{\kappa}^{2}}} \sqrt{\frac{2}{\rho}} \sqrt{\left|p_{\mathrm{H}}-p_{\mathrm{BC}}\right|}\right] ; \\
& k_{\phi}=\left[(\mu f)_{\phi} \sqrt{\frac{2}{\rho(P, T)}} \sqrt{p_{\phi}-p_{\mathrm{L}}}\right] /\left[(\mu f)_{\phi} \sqrt{\frac{2}{\rho}} \sqrt{p_{\phi}-p_{\mathrm{L}}}\right] \\
& k_{1}=\frac{z_{1}}{z_{1}^{\prime}} ; \quad k_{2}=\frac{z_{2}}{z_{2}^{\prime}} ; \quad k_{3}=\frac{z_{3}}{z_{3}^{\prime}},
\end{aligned}
$$

where $z_{1}^{\prime}, z_{2}^{\prime}, z_{3}^{\prime}$ are fuel leakages at a temperature of $\mathrm{T}_{\mathrm{H}}, \mathrm{T}_{\mathrm{H}}, \mathrm{T}_{\phi}$, respectively.

Thus, a conclusion can be made that taking into account the change in volume due to the heat-generated expansion of fuel in compression cavities $\left(\beta \cdot V \frac{d T}{d t}\right)$ and the effect of the temperature on the fuel consumption through throttling elements in the boundary equations with the use of the adjustment coefficients provides more relevant description of the real process of fuel flow in the HPL during its injection. However, the use of composite rapeseed-mineral fuel makes its own adjustments to the equations of volume balance of boundary conditions, since the physical and chemical properties of such fuel directly depend on its composition.

As it shows, in the theoretical justification of the diesel fuel injection process, the fuel consumption coefficient $\mu$ is used, which depends on the fuel viscosity that is represented via the Reynolds number Re and is calculated according to the formula:

$$
\mu=\frac{1}{1,23+\frac{58 l}{\mathrm{R}_{\mathrm{e}} \mathrm{d}}},
$$

where $l$ is the fuel tubing length, $\mathrm{m}$; $d$ is the internal diameter of the fuel tubing, $\mathrm{m} ; R_{e}$ is the Reynolds number.

Generally, the Reynolds number is determined by the following inter-relation:

$$
R e=\frac{\rho \vartheta L}{\eta}=\frac{\vartheta L}{v}=\frac{Q L}{v f},
$$

where $\mathrm{L}$ is the characteristic size, $\mathrm{m} ; \rho$ is the medium density, $\mathrm{kg} / \mathrm{m}^{3} ; \mathrm{v}$ is the velocity, $\mathrm{m} / \mathrm{s} ; \eta$ is the dynamic viscosity, $\mathrm{N} \cdot \mathrm{s} / \mathrm{m}^{2} ; v$ is the kinematic viscosity, $\mathrm{m}^{2} / \mathrm{s}(v=\eta / \rho) ; \quad Q$ is the volumetric flow rate, $\mathrm{m}^{3} / \mathrm{s}$; $\mathrm{f}$ is the line flow area, $\mathrm{m}^{2}$.

Having applied the final expression of the Reynolds number from the expression (1.6) in the formula for the flow coefficient calculation (1.5), we get: 


$$
\mu=\frac{1}{1,23+\frac{58 l}{\frac{Q L}{v f} \mathrm{~d}}}=\frac{1}{1,23+\frac{58 l v f}{Q L \mathrm{~d}}} .
$$

Kinematic viscosity of composite diesel rapeseed-mineral fuel

$$
v_{F}=\frac{\left(m_{D F}+m_{R O}\right) v_{D F} \cdot v_{R O}}{m_{D F} \cdot v_{R O}+m_{R O} \cdot v_{D F}}, \quad \mathrm{~m}^{2} / \mathrm{s},
$$

where $\mathrm{m}_{\mathrm{df}}$ is the weight of mineral diesel fuel in the composition, $\mathrm{kg} ; \mathrm{m}_{\mathrm{ro}}$ is the weight of rapeseed fuel, $\mathrm{kg} ; v_{\mathrm{df}}$ is the kinematic viscosity of diesel fuel, $\mathrm{m}^{2} / \mathrm{s} ; v_{\text {ro }}$ is the kinematic viscosity of rapeseed fuel, $\mathrm{m}^{2} / \mathrm{s}$.

Density of composite diesel rapeseed-mineral fuel:

$$
\rho_{F}=\frac{m_{D F}+m_{R O}}{\frac{m_{D F}}{\rho_{D F}}+\frac{m_{R O}}{\rho_{R O}}}, \quad \mathrm{~kg} / \mathrm{m}^{3},
$$

where $\rho_{\text {df }}$ is the density of diesel fuel, $\mathrm{kg} / \mathrm{m}^{3} ; \rho_{\text {ro }}$ is the density of rapeseed fuel, $\mathrm{kg} / \mathrm{m}^{3}$.

It was found out from the analysis of literary sources that the dependence of the fuel density on its temperature is represented by the expression.

$$
\rho_{F}=\rho_{0}-0,00076(\mathrm{~T}-20), \mathrm{kg} / \mathrm{m}^{3},
$$

where $\rho_{0}$ is the fuel density under normal conditions, $\mathrm{kg} / \mathrm{m}^{3} ; \mathrm{T}$ is the fuel temperature in the given compression chamber, $K$.

When deriving the formula for calculating the dynamic viscosity at high pressure, A. S. Keramidi is based on the assumption that viscosity increases linearly with increase in pressure:

$$
\eta_{\mathrm{T}}=\eta_{\text {т н.у. }}+\left(\frac{d \eta}{d p}\right)_{\mathrm{T}}^{\mathrm{cp}}\left(p-p_{0}\right), \mathrm{Pa} \cdot \mathrm{s},
$$

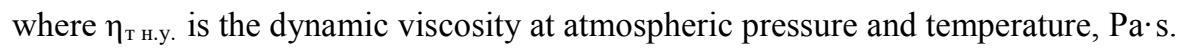

The derivative $\left(\frac{d \eta}{d p}\right)_{\mathrm{T}}^{\mathrm{cp}}$ decreases with increase in the temperature according to the following rule:

$$
\left(\frac{d \eta}{d p}\right)_{\mathrm{T}}^{\mathrm{cp}}=\frac{1}{a+b \mathrm{~T}},
$$

where $\mathrm{a}$ and $\mathrm{b}$ are experimental coefficients depending on the nature of the substance which are determined by two viscosity values at two temperature values.

Therefore, the dynamic viscosity depends on the temperature and pressure.

$$
\eta_{R F}=\eta_{\text {т н.у. }}+\frac{1}{a+b \mathrm{~T}}\left(p-p_{0}\right)
$$

Therefore, equation (1.13) allows for calculating the dynamic viscosity depending on the temperature and pressure with the deviation of the calculated viscosity values from the experimental ones not exceeding $\pm 3 \%$.

In order to adequately calculate the fuel supply parameters of a diesel engine running on composite rapeseed-mineral fuel, the formulas $(1.7,1.8,1.9,1.10$ and 1.13) shall be included into the calculation.

Then we will get the final form of the formula that allows for calculating the kinematic viscosity of composite rapeseed-mineral fuel depending on the DCF composition, density, temperature, and pressure: 


$$
\begin{gathered}
v_{F}=\left(m_{D F}+m_{R O}\right)\left(p+a \eta_{\mathrm{T} D F}+b \mathrm{~T} \eta_{\mathrm{T} D F}-p_{0}\right)\left(p+a \eta_{\mathrm{T} R O}+b \mathrm{~T} \eta_{\mathrm{T} R O}-p_{0}\right) /((a+b \mathrm{~T}) \\
\times\left(0,0152 p m_{D F}-0,0152 p_{0} m_{R O}-0,0152 p_{0} m_{D F}+0,0152 p m_{R O}+p \rho_{0 D F} m_{D F}+\right. \\
+p \rho_{0 R O} m_{R O}-0,00076 p \mathrm{~T} m_{D F}-0,00076 p \mathrm{~T} m_{R O}-p_{0} \rho_{0 D F} m_{D F}-p_{0} \rho_{0 R O} m_{R O}+ \\
+0,00076 p_{0} \mathrm{~T} m_{D F}+0,00076 p_{0} \mathrm{~T} m_{D F}+0,0152 a \eta_{\mathrm{T} D F} m_{R O}+0,0152 a \eta_{\mathrm{T} R O} m_{D F}+ \\
+a \rho_{0 D F} \eta_{\mathrm{T} R O} m_{D F}+a \rho_{0 R O} \eta_{\mathrm{T} D F} m_{R O}-0,00076 a \mathrm{~T} \eta_{\mathrm{T} D F} m_{D F}-0,00076 a \mathrm{~T} \eta_{\mathrm{T} R O} m_{D F}+ \\
+0,0152 b \mathrm{~T} \eta_{\mathrm{T} D F} m_{R O}+0,0152 b \mathrm{~T} \eta_{\mathrm{T} R O} m_{D F}-0,00076 b \mathrm{~T}^{2} \eta_{\mathrm{T} D F} m_{R O}- \\
\left.\left.+b \mathrm{~T} \rho_{0 R O} \eta_{\mathrm{T} D F} m_{R O}\right)\right), \quad \mathrm{mm}^{2} / \mathrm{s} \quad-0,00076 \mathrm{~T}^{2} \eta_{\mathrm{T} R O} m_{D F}+b \mathrm{~T} \rho_{0 D F} \eta_{\mathrm{T} R O} m_{D F}
\end{gathered}
$$

The value of the volumetric supply can be determined from the system of equations (1.2), namely, from the equation of volume balance in the discharge chamber. But to take into account the DCF composition and changes in its density depending on the temperature and pressure, we shall combine equations (1.9) and (1.10) to get the following:

$$
\rho_{\mathrm{T}}=\left(\frac{m_{D F}+m_{R O}}{\frac{m_{D F}}{\rho_{0 D F}}+\frac{m_{R O}}{\rho_{0 R O}}}\right)-0,00076(\mathrm{~T}-20), \quad \mathrm{kg} / \mathrm{m}^{3} .
$$

Having applied the obtained expression (1.15) in the equation of volume balance in the discharge chamber from the system of equations (1.2), we obtain the refined equation of volume balance in the discharge chamber:

$$
\begin{aligned}
& \gamma_{\mathrm{H}} V_{H} \frac{d p_{H}}{d t}= f_{\Pi} C_{\Pi}-k_{0}(\mu f)_{0} \sqrt{\frac{2}{\left(\frac{m_{D F}+m_{R O}}{\rho_{0 D F}}+\frac{m_{R O}}{\rho_{0 R O}}\right)-0,00076(\mathrm{~T}-20)}} \sqrt{\left|p_{\mathrm{H}}-p_{\mathrm{вс}}\right|}- \\
&-k_{\text {щ }}(\mu f)_{\text {щ }} \sqrt{\frac{1}{1-k_{\kappa}^{2}}} \sqrt{\frac{2}{\left(\frac{m_{D F}+m_{R O}}{\left.\frac{m}{D F}_{\rho_{0 D F}}+\frac{m_{R O}}{\rho_{0 R O}}\right)}-0,00076(\mathrm{~T}-20)\right.}-f_{\kappa} \frac{d y}{d t}-} \\
&-\frac{1}{k_{1}} z_{1}-\frac{1}{k_{2}} z_{2}+\beta_{H} V_{H} \frac{d T_{H}}{d t} .
\end{aligned}
$$

When calculating the volumetric supply with the use of the formula (1.16), it is shall be taken into account that the coefficient of consumption of composite rapeseed-mineral fuel is determined from the expression (1.7) with account for the kinematic viscosity determined according to the formula (1.14).

In a similar manner, all equations of volume balance included in the systems of equations (1.2) and (1.3) will change.

Also, the use of composite rapeseed-mineral fuel due to its physical and chemical properties, will adjust the equations of the adjustment coefficients which take the fuel leakage into account. Then, the formulas (1.4) will look as follows: 


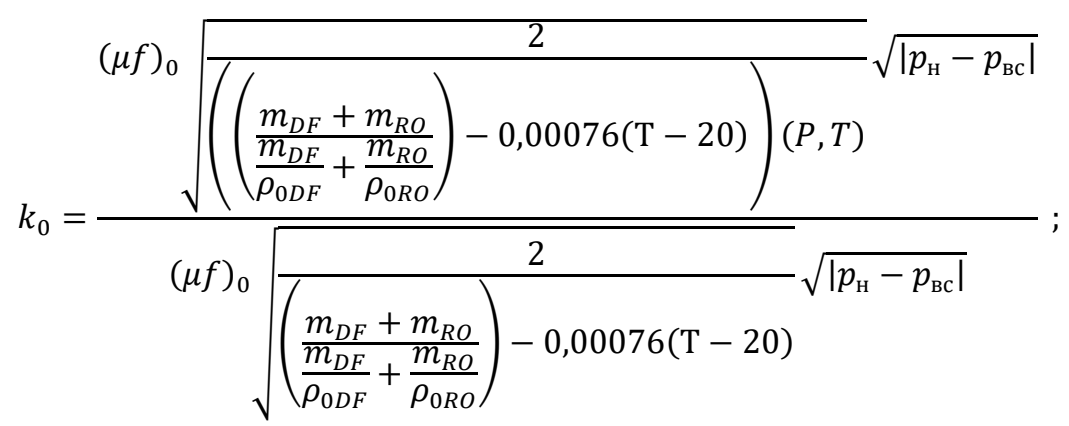

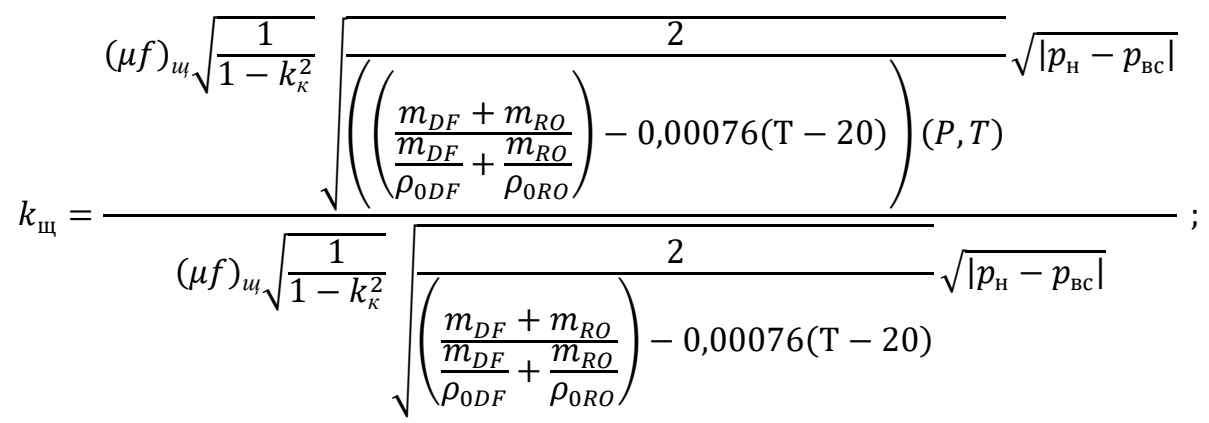

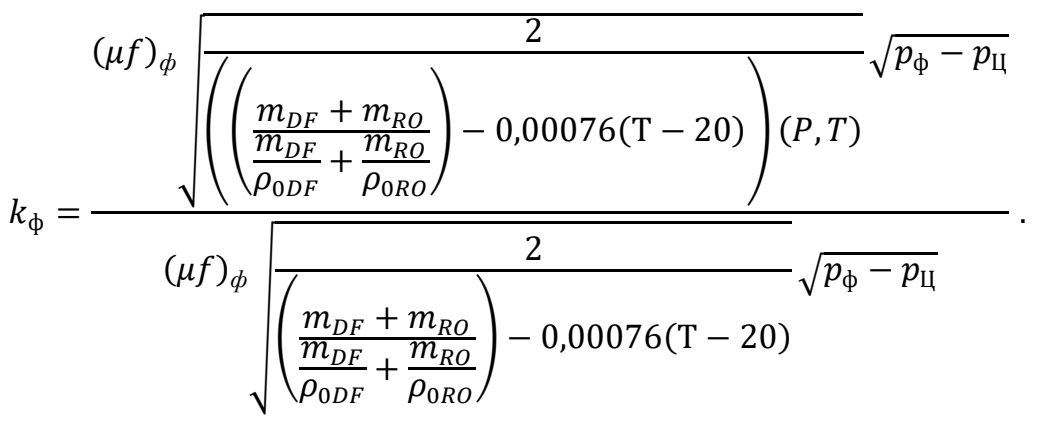

Let us determine the speed of passage of the pressure wave of composite rapeseedmineral fuel through the pressure fuel tubing depending on its composition, temperature and pressure:

a $=\mu_{\mathrm{T}} \sqrt{\frac{\left(2 \mathrm{p}_{\mathrm{H}}^{\prime}-2 \mathrm{p}_{\mathrm{H}}^{\prime \prime}\right) \cdot\left(\rho_{0 D F} m_{R O}+\rho_{0 R O} m_{D F}-0,00076\left(\mathrm{~T}_{D F}-\mathrm{T} m_{R O}\right)+0,0152\left(m_{D F}+m_{R O}\right)\right)}{\left(m_{D F}+m_{R O}\right) \cdot\left(-0,00076 \mathrm{~T}+\rho_{0 D F}+0,0152\right) \cdot\left(-0,00076 \mathrm{~T}+\rho_{0 R O}+0,0152\right)}}, \mathrm{m}$ /s. (1.19)

The pressure at the inlet to the pressure fuel tubing $\mathrm{p}_{\text {н }}$ ' is determined from the system of equations (1.2), namely, from the equation of volume balance in the valve chamber.

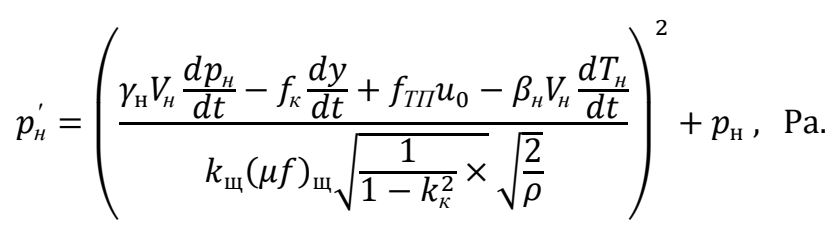


According to the rule of flow continuity preservation, the geometric flow through the pressure fuel tubing shall be the same over its total length; then in the resulting equation the product $f_{\text {тп }} \mathrm{u}_{0}$ can be replaced with $(\mu \mathrm{f})_{\mathrm{тп}}$. Having combined the expression $(1.20)$ with the expression (1.15), we obtain the dependence of the fuel pressure at the outlet to the pressure fuel tubing (at the outlet from the HPFP nozzle) on the DCF composition, its temperature and pressure:

$$
\begin{aligned}
& p_{H}^{\prime}=\left(\frac{\gamma_{\mathrm{H}} V_{H} \frac{d p_{H}}{d t}-f_{\kappa} \frac{d y}{d t}+(\mu f)_{\mathrm{T \Pi}}-\beta_{H} V_{H} \frac{d T_{H}}{d t}}{2} \sqrt{k_{\text {щ }}(\mu f)_{щ} \sqrt{\frac{1}{1-k_{\kappa}^{2}} \times} \sqrt{\frac{\left(\frac{m_{D F}+m_{R O}}{\left.\frac{m_{D F}}{\rho_{0 D F}}+\frac{m_{R O}}{\rho_{0 R O}}\right)}-0,00076(\mathrm{~T}-20)\right.}{2}}}\right)^{2} \\
& +p_{\mathrm{H}}, \mathrm{Pa} \text {. }
\end{aligned}
$$

Fuel pressure at the outlet of the pressure fuel tubing (at the nozzle inlet)

$$
\mathrm{p}_{\mathrm{H}}^{\prime \prime}=p_{H}^{\prime}-\Delta P, \quad \mathrm{~Pa} .
$$

where $\Delta \mathrm{P}$ is loss of fuel pressure over the length of the pressure fuel tubing, $\mathrm{Pa}$.

In turn, the pressure loss associated with overcoming the friction forces during fuel flow through the pressure fuel tubing is determined according to the well-known formula:

$$
\Delta P=\lambda \frac{L \rho \omega^{2}}{2 D}, \quad \mathrm{~Pa} .
$$

where $\lambda$ is the pipe friction number; $\mathrm{L}$ and $\mathrm{D}$ are the pipeline length and internal diameter, $\mathrm{m} ; \rho$ is the fuel density, $\mathrm{kg} / \mathrm{m}^{3} ; \omega$ is the mean volumetric flow rate, $(\mathrm{m} / \mathrm{s})$ determined by the flow $\mathrm{Q},\left(\mathrm{m}^{3} / \mathrm{s}\right)$ :

$$
\omega=\frac{4 Q}{\pi D^{2}}, \mathrm{~m} / \mathrm{s}
$$

Having applied the formula (1.23) in the equation (1.24), we get:

$$
\Delta P=\lambda \frac{L \rho\left(\frac{4 Q}{\pi D^{2}}\right)^{2}}{2 D}=\lambda \frac{16 L \rho Q^{2}}{2 \pi^{2} D^{5}}, \quad \mathrm{~Pa} .
$$

By combining the formulas (1.25) and (1.15), we obtain the equation of dependence of pressure loss over the length of the fuel tubing on the composition of composite rapeseedmineral fuel, its temperature and pressure:

$$
\Delta P=\lambda \frac{16 L Q^{2}\left(\left(\frac{m_{D F}+m_{R O}}{\frac{m_{D F}}{\rho_{0 D F}}+\frac{m_{R O}}{\rho_{0 R O}}}\right)-0,00076(\mathrm{~T}-20)\right)}{2 \pi^{2} D^{5}}, \quad \mathrm{~Pa} .
$$

\section{Calculation results}

The fuel supply parameters were calculated with the use of the refined mathematical model on a PC in the updated "INJECTION" software package developed by the N.E. Bauman 
Moscow State Technical University.

The calculations show (Fig. 1) that the kinematic viscosity of composite diesel rapeseed-mineral fuel varies significantly depending both on the content of rapeseed oil in the fuel and on changes in its temperature and pressure. An increase in fuel temperature leads to a significant decrease in kinematic viscosity. The higher the temperature, the less effect has the concentration of rapeseed oil in composite diesel rapeseed-mineral fuel on the kinematic viscosity.

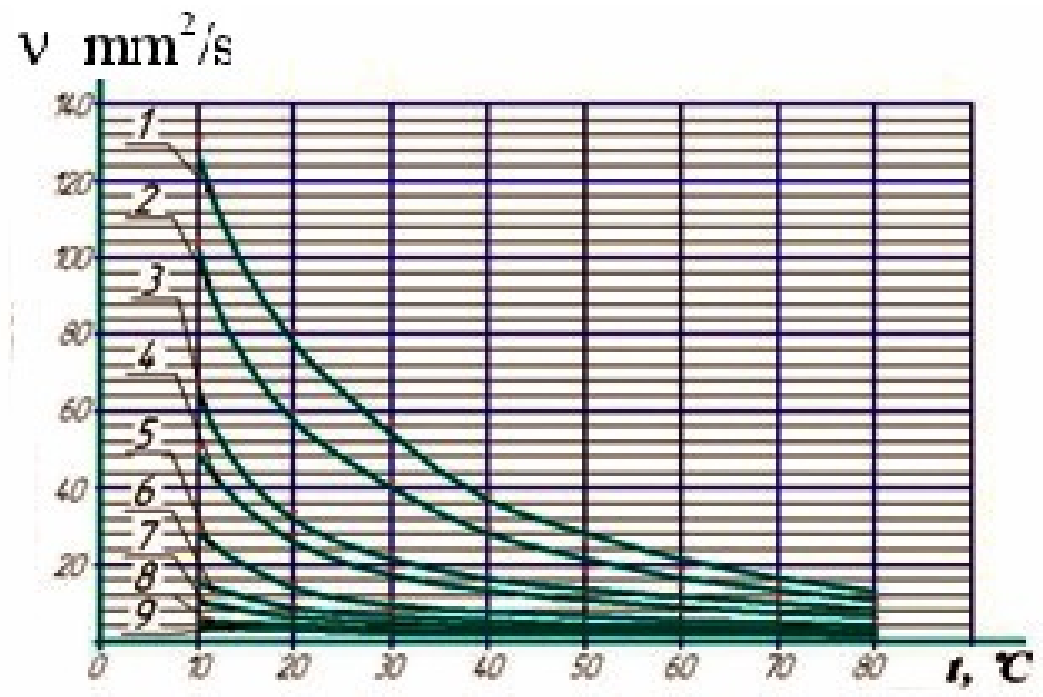

Fig. 1. Change in the kinematic viscosity $v$ of composite diesel rapeseed-mineral fuel at a positive temperature $\mathrm{t}: 1-100 \% \mathrm{RO}$,

$2-90 \%$ RO $+10 \% \mathrm{DF}, 3-75 \% \mathrm{RO}+25 \% \mathrm{DF}, 4-63 \% \mathrm{RO}+37 \% \mathrm{DF}, 5-50 \% \mathrm{RO}+50 \% \mathrm{DF}, 6-$ $37 \% \mathrm{RO}+63 \% \mathrm{DF}$,

$7-25 \% \mathrm{RO}+75 \% \mathrm{DF}, 8-10 \% \mathrm{RO}+90 \% \mathrm{DF}, 9-100 \% \mathrm{DF}$

With a change in the kinematic viscosity, the DCF density and flow coefficients are also changed, which in turn are used in the phase-by-phase calculation of the fuel supply parameters. The calculations showed (Fig. 2) that the fuel pressure at the outlet of the HPFP nozzle depends on both the percentage composition of rapeseed-mineral fuel and change in its temperature. Moreover, an increase in the temperature of composite rapeseed-mineral fuel makes it possible to compensate the increase in the fuel pressure at the outlet of the HPFP nozzle caused by an increase in the volumetric content of rapeseed oil in DCF. 


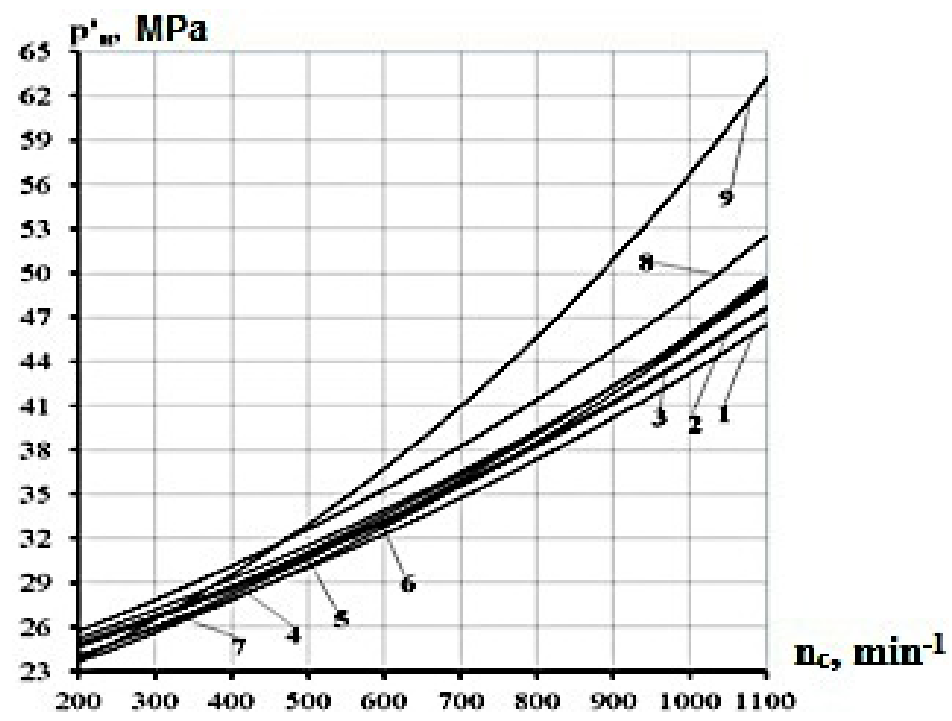

Fig. 2. Change in fuel pressure at the outlet of HPFP nozzle at a positive temperature: $1-100 \% \mathrm{DF}$ $30^{\circ} \mathrm{C}, 2-10 \%$ RO $30^{\circ} \mathrm{C}, 3-25 \% \mathrm{RO} 50^{\circ} \mathrm{C}, 4-37 \% \mathrm{RO} 60^{\circ} \mathrm{C}, 5-50 \% \mathrm{RO} 70^{\circ} \mathrm{C}, 6-63 \% \mathrm{RO} 80^{\circ} \mathrm{C}$, $7-75 \%$ RO $80^{\circ} \mathrm{C}, 8-90 \%$ RO $80^{\circ} \mathrm{C}, 9-100 \%$ RO $80^{\circ} \mathrm{C}$

This trend is preserved until DCF with a $75 \%$ content of rapeseed oil is heated to a temperature of $80{ }^{\circ} \mathrm{C}$. With a further increase in the rapeseed concentration in DCF up to $90 \%$ and $100 \%$, heating to a temperature more than $80{ }^{\circ} \mathrm{C}$ is required, which is almost impossible in the field conditions due to significant heat losses and an increased risk of failure of the diesel engine equipment.

A similar situation is observed when calculating the volumetric cycled fuel supply (Fig. 3).

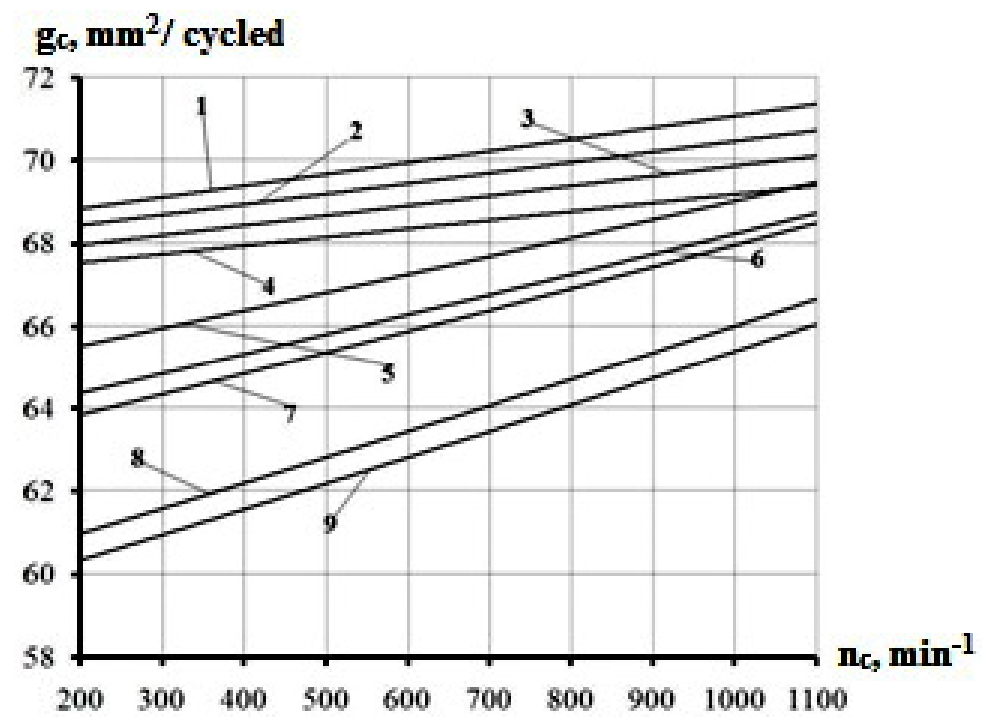

Fig. 3. Change in the volumetric cycled fuel supply at a positive temperature: $1-100 \% \mathrm{DF} 30^{\circ} \mathrm{C}, 2-$ $10 \%$ RO $30^{\circ} \mathrm{C}, 3-25 \%$ RO $50^{\circ} \mathrm{C}, 4-37 \%$ RO $60^{\circ} \mathrm{C}, 5-50 \%$ RO $70^{\circ} \mathrm{C}, 6-63 \%$ RO $80^{\circ} \mathrm{C}, 7-75 \% \mathrm{RO}$ $80^{\circ} \mathrm{C}, 8-90 \% \mathrm{RO} 80^{\circ} \mathrm{C}, 9-100 \% \mathrm{RO} 80^{\circ} \mathrm{C}$

An increase in the temperature of composite diesel rapeseed-mineral fuel makes can 
compensate for the decrease in the volumetric cycled fuel supply caused by an increase in the concentration of rapeseed oil in it. However, heating of composite fuel can not compensate for its volumetric cycled supply if a content of rapeseed oil in the fuel exceeds $67 \%$. This is mainly due to the increase in the density of composite rapeseed-mineral fuel with the increase in pressure. Another important factor is its high viscosity at a concentration of rapeseed oil more than $67 \%$.

The calculations also illustrate the change in time and speed of pressure wave passing through the pressure fuel tubing (Fig. 4) with an increase in the concentration of rapeseed oil in composite rapeseed-mineral fuel, taking into account the effects of temperature and fuel pressure.

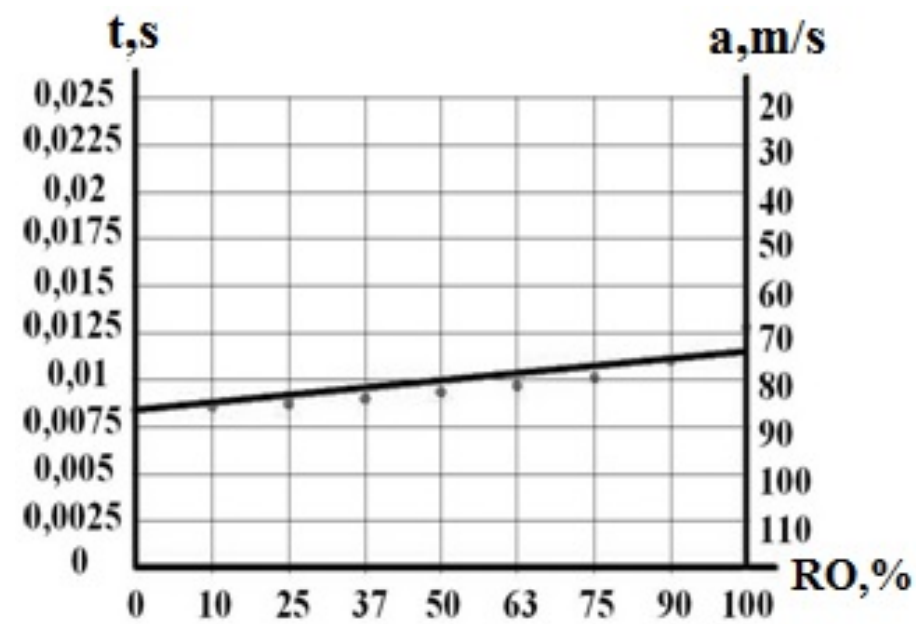

Fig. 4. Change in time and speed of pressure wave passing through the pressure fuel tubing with an increase in the concentration of rapeseed oil in composite rapeseed-mineral fuel

The analysis of the graph (Fig. 4) shows that there is a direct relationship, which means that the higher the concentration of rapeseed oil in composite rapeseed-mineral fuel, the longer the duration and the lower the speed of the pressure wave of the fuel passing through the pressure fuel tubing.

\section{Conclusion}

The resulting mathematical model allows us to characterize the entire working process of fuel supply during the operation of diesel on a mixed rapeseed-mineral fuel at any temperature and any percentage composition.

\section{References}

1. A.S. Averyanov, A.P. Ukhanov, E.G. Rotanov, Theoretical and experimental estimation of influence of diesel composite fuel on the fuel supply parameters, News of the Samara state agricultural academy, v. 3, pp. 97-101 (2011)

2. A.S. Averyanov, A.P. Ukhanov, Theoretical and experimental estimation of influence of heating of diesel composite fuel on cycle fuel supply and fuel pressure in above-plunger space of a high-pressure fuel pump (HPFP), Announcer of the Ul'yanovskoy state agricultural academy, v. 4, pp. 110-113 (2012)

3. A.S. Averyanov, A.P. Ukhanov, Dependence of diesel fuel apparatus on 
composition by percentage of composite fuel, Collection of materials of the All-russian scientific and practical conference of young scientists «Contribution of young scientists to innovative development of agroindustrial complex of Russia», pp. 29-30 (2009).

4. A.S. Averyanov, A.P. Ukhanov, Research of physical properties of composite rapeseed-mineral fuel at different temperatures, Collection of materials of the Allrussianian scientific and practical conference of «Achievement and prospect of development of biotechnology», pp. 9-13 (2010).

5. A.S. Averyanov, E.G. Rotanov, Results of stand wear tests of plunge pair of fuel pump of 4UTNM rapeseed-mineral and composite fuel, Collection of materials of the Allrussian scientific and practical conference of young scientists «Contribution of young scientists to innovative development of agroindustrial complex of Russia», pp. 273-274 (2011).

6. A.S. Averyanov, A.P. Ukhanov, Influence of different compositions of diesel composite fuel and speed mode on fuel pressure in above-plunger space of high-pressure fuel pump (HPFP), Materials of the All-russian scientific and practical conference of young scientists, graduate students «Innovative ideas of young scientists for the agroindustrial complex of Russia», pp. 19-22 (2012).

7. A.P. Ukhanov, D.À. Ukhanov, V.A. Rachkin, V.A. Ivanov, Estimation of lower heat of combustion of rape-seed mineral oil and mineral-vegetable fuels, Collection of materials of the International scientific and practical conference «Education, science, practice: innovative aspect», pp. 181-184 (2008).

8. A.S. Averyanov, A.P. Ukhanov, Theoretical and experimental estimation of influence of composition of diesel composite fuel on on cycle fuel supply of a high-pressure fuel pump (HPFP), Materials of International scientific and technical council of V.V. Mikhaylov «Problem of economy and exploitation of motor-vehicles and tractors », pp 266268 (2012).

9. A.S. Averyanov, A.S. Averyanov, D.A. Ukhanov, Estimation of dependence of fuel pressure in above-plunger space of high-pressure fuel pump (HPFP) from composition of diesel composite fuel and change of rotation frequency of a HPFP camshaft, Materials of internationa scientific and practical conference «Science in modern terms: from an idea to implementation», pp. 119-122 (2012). 